\title{
Stories From the Field
}

\section{The Heavy Toll of COVID-19 in Bolivia: A Tale of Distrust, Despair, and Health Inequalities}

\author{
Víctor Villarroel Saavedra, ${ }^{1,2}$ Mónica Arebalo López, ${ }^{3}$ and Nicolás Dauby ${ }^{4,5 \star}$ \\ ${ }^{1}$ Neurology Department, Hospital Elizabeth Seton, Caja Petrolera de Salud, Cochabamba, Bolivia; ${ }^{2}$ University of Aquino Bolivia, Cochabamba, \\ Bolivia; ${ }^{3}$ Intensive Care Department, Arebalo Clinic, Cochabamba, Bolivia; ${ }^{4}$ Department of Infectious Diseases, CHU Saint-Pierre, Université Libre \\ de Bruxelles, Brussels, Belgium; ${ }^{5}$ School of Public Health, Université Libre de Bruxelles (ULB), Brussels, Belgium
}

The story of my father started in July 2020 when he presented mild symptoms compatible with coronavirus 2019 (COVID-19) (cough and fever). He started self-medicating with painkillers and non-steroidal anti-inflammatory drugs. In Bolivia, selfmedicating is widespread among the population. As in other Latin American countries, there was a widespread use of chlorine dioxide, a derivative of bleach. The use of this potentially toxic chemical was even promoted by the government. Indeed, in July 2020, the Bolivian Senate approved a law that allowed the production, distribution, and use of chlorine dioxide for the prevention and treatment of severe acute respiratory syndrome coronavirus 2 (SARS-CoV-2) infection. Consumption of medicinal plant-based products to prevent or cure SARS-CoV-2 infection is frequent in some communities and has been also promoted. Former president Evo Morales, who had recently returned from exile in Argentina as a result of the political unrest surrounding the disputed elections in November 2019 , promoted the use of medicinal plant-based products on his Twitter account after his diagnosis of COVID-19.

One week after my father presented with mild symptoms, he developed shortness of breath and fever, and his oxygen saturation was $90 \%$. My father, like many Bolivians who got sick with COVID-19, strongly refused to be hospitalized. Distrust from the general population toward the health-care system is indeed endemic, fueled by reports in the press that highlight the high mortality rate in hospitalized patients. As a result, patients and their relatives delay consulting a doctor. Fortunately, we were able to provide care at home. Because of this distrust toward the health system, but also the saturation of the hospitals, many patients diagnosed in Bolivia prefer to get treatment at home, buying oxygen tanks and hiring private nurses and doctors to provide this care. For my father, early treatment included intravenous fluids and oxygen administration through nasal cannula. A blood test was performed, but essential analyses such as D-dimers could not be carried out because of the shortage of reactive agents. A rapid antigen test for SARSCoV-2 was performed and returned positive. Although we could afford to pay for a SARS-CoV-2 diagnosis test, this is not the case for the majority of the Bolivian population. The price of SARS-CoV-2 reverse transcription-polymerase chain reaction (RT-PCR) testing is around USD100. The costs are covered only for owners of private insurance, who represent less than $40 \%$ of the population. In the public sector, only limited numbers of RT-PCR tests could be performed not only because of the price, but also because of reagent shortage, thereby limiting access to testing for most infected subjects because they cannot afford it. The underdiagnosed subjects likely *Address correspondence to Nicolás Dauby, Department of Infectious
Diseases, CHU Saint-Pierre, Rue Haute 322,1000 Brussels, Université
Libre de Bruxelles, Brussels, Belgium. E-mail: nicolas.dauby@ stpierre-bru.be contribute to virus dissemination and to the underestimation of its spread throughout the Bolivian population.

Despite being treated with low-weight heparin derivatives and antibiotics at home, my father's condition deteriorated. We had to fight hard to convince him to be hospitalized. Like him, many patients had delayed access to care because, in their minds, intensive care unit (ICU) admission is equivalent to a death sentence.

We had to rent an ambulance and then wander between clinics and hospitals while we made phone calls to these institutions, looking for a place where he could be given medical care. Since the beginning of the pandemic, it is up to the population to find appropriate health care. There is no emergency medical care system. The cost of ambulance transfers within the city of Cochabamba and between hospitals is around USD500 for COVID-19 patients. At night, when we thought we had finally found a place where he could be hospitalized, we went through another period of anxiety and despair when the oxygen available in the ambulance ran out. When we finally arrived at the small clinic, we were told my father actually needed middle-to-intensive care, which was not available at the clinic. For 2 days, we continued to search for a health-care institution that could provide middle-to-intensive care, but all institutions were saturated. We had to buy a bilevel positive airway pressure machine, which we provided to the clinic, and later purchased a high-flow oxygen concentrator. As in other Latin America countries, oxygen is a precious commodity and needs to be imported with the help of the Pan American Health Organisation to counter the shortage. Although my father initially showed signs of stabilizing, he later deteriorated again.

Finally, thanks to the help of strangers, we found a bed in the ICU of the University Hospital Viedma. There, my father continued to benefit from high-flow therapy for 36 hours. But, on August 3rd, he was intubated and put on mechanical ventilation. The nightmare went on. We knew from relatives who were in the same situation as us that there was a significant shortage of drugs. Every day, from dawn until dusk, we searched from one pharmacy to the next for essential drugs such as benzodiazepines, opioids, low-weight heparin derivatives, and neuromuscular blocking agents. Every day it was more difficult to find medications, and prices were rising. In Bolivia, desperate families spend significant amounts of money on drugs with limited or no evidence of their efficacy, such as remdesivir or convalescent plasma. Families looking for plasma for their relatives post requests for bloodcompatible plasma donors on Facebook. Donors are offered cash (up to USD10,000 for one donation of plasma) or even jobs in exchange for plasma. At the same time, with the political disruption following the controversial elections, a large section of the population defied the government's lockdown, restriction of movement, and even mask wearing. Protests and road blockades contributed to the scarcity of drugs and 
oxygen. This led the interim government to pass laws to criminalize any activity that would defy the lockdown measures.

My father was hospitalized in a public institution that was saturated with patients and lacked essential medication. Had we wanted to hospitalize him in a private hospital, we would have spent an excessive amount of money. To secure access to private clinics, there has to be a down payment at the time of admission (USD650/day for a spot in a COVID-19 ward and up to USD1,500/day for ICU). This amount largely exceeds the minimum wage in Bolivia (USD305/month).

Despite intensive care admission and mechanical ventilation, my father died after 1 week. My father was a doctor. As in other Latin America countries, health-care workers (HCWs) have also paid a heavy toll. An estimated 175 doctors have died since the beginning of the pandemic in Bolivia, with a population of 11 million inhabitants.

The heavy toll of the COVID-19 pandemic in Bolivia reflects this combination of distrust toward authorities and HCWs. The profound health inequalities limit access to hospitals and testing, and create desperate measures such as self-medication and the production of fraudulent medications. Recently, protests by medical doctors broke out in the country because of unpaid wages.

The observations and experiences related to COVID-19 in this story from the field are not exclusive to Bolivia, and are probably found in other countries of Latin America and around the world with similar sociological and economic structures.
This story also illustrates Bolivia's mismanagement of the COVID-19 pandemic from political, economic, and public health aspects, and highlights the importance of appropriate directives for the prevention and treatment of the virus, the allocation of financial intervention from the government for appropriate testing and treatment, and the need to invest in a resilient health-care system.

Received January 24, 2021. Accepted for publication March 28, 2021.

Published online April 9, 2021.

Acknowledgments: We warmly thank Dr. Sheila Cattell for English language revision and editing. N. D. is a post-doctorate clinical master specialist of the F.R.S-FNRS.

Authors' addresses: Víctor Villarroel Saavedra, Neurology Department, Hospital Elizabeth Seton, Caja Petrolera de Salud, Cochabamba, Bolivia, and the University of Aquino Bolivia, Cochabamba, Bolivia, E-mail: virubom@hotmail.com. Mónica Arebalo López, Intensive Care Department, Arebalo Clinic, Cochabamba, Bolivia, E-mail: monicaarebalo@gmail.com. Nicolás Dauby, Department of Infectious Diseases, CHU Saint-Pierre, Université Libre de Bruxelles, Brussels, Belgium, and the School of Public Health, Université Libre de Bruxelles, Brussels, Belgium, E-mail: nicolas_dauby@stpierrebru.be.

This is an open-access article distributed under the terms of the Creative Commons Attribution (CC-BY) License, which permits unrestricted use, distribution, and reproduction in any medium, provided the original author and source are credited. 